\title{
Um quase manifesto contra a especialização
}

\author{
Eduarda Dionísio
}

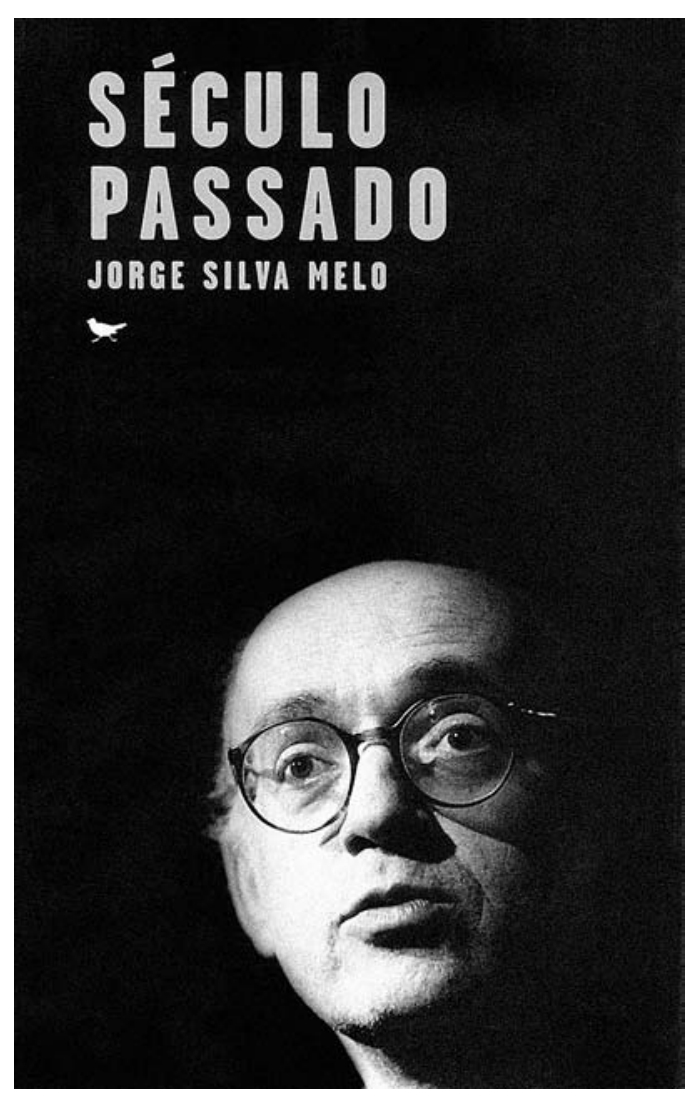

1.

Não é fácil escrever sobre um livro como Século passado que não foi escrito para se escrever sobre ele mas para ser lido: primeiro, antes de ser livro, quase todo espalhado por páginas de jornais e de revistas e de algumas publicações não periódicas; depois, quando já é o calhamaço em que se tornou - depurado, completado, arrumado (por capítulos como é próprio dos livros), corrigido (reescrito), e com um caderno de belas fotografias de uma vida, e luxuosamente encadernado. Livro que até tem uma fitinha preta com que podemos marcar o andamento da leitura (lento ou rápido, ou salteado, depende), instrumento e decoração, a que já não estávamos habituados. Com o formato do guardar, contrário ao lere-deitar-fora, uma vez por semana, uma vez por mês, que começou por ter.
Jorge Silva Melo, Século passado, Lisboa, Edições Cotovia, 2007, 536 pp + caderno de fotos (não numerado) de $24 \mathrm{pp}$.

\begin{abstract}
colaboração regular: no Público sairam perto de metade dos textos aqui publicados (mais de cinquenta no extinto suplemento Mil folhas); no Magazine artes, uma vintena; em Epidur, sete. Outros textos, em número muito inferior, resultam de colaborações menos prolongadas ou mais esporádicas em diários (A capitaf), em semanários (Expresso, Sol, Vida mundial, JL), em revistas de literatura e artes (Meus livros, Fictions, Relâmpago) e em publicações de caracteristicas mais militantes (Gazeta do mês, Combate, Revista Abril em Maio, PREC). Cerca de 20 são textos escritos para catálogos (de pintores, muitos de cinema) ou são "folhas de sala" de ciclos de cinema na Cinemateca e na Gulbenkian. Um texto foi um discurso.
\end{abstract}

São 12 os capitulos, e 12 não é um número qualquer. Todos eles têm uma introdução: um texto já escrito que passou a ter essa função ou um texto (inédito) escrito para ser introdução. E é um livro com "epilogo".

2.

É esta a primeira dificuldade: pega-se (alguns pegarão) neste livro com menos curiosidade do que noutros, com o pressuposto do déjá lu, mais para reconhecer, confirmar, lembrar, do que para descobrir. Já o conhecíamos (ou poderíamos conhecer), todo (ou quase), ou assim julgamos (se formos leitores de certas publicações e do Autor), uma vez que quase todos os textos aqui reunidos já tinham sido publicados.

Depressa se vê que não é afinal uma colectânea de artigos (ou de crónicas), uma daquelas mantas de retalhos com ordem cronológica, com que os Autores que escrevem na imprensa têm a tentação de lutar contra a tristeza do efémero - e assim ficarem para a História. Há em Século passado trabalho bem concreto, para lá de uma meia dúzia de textos inéditos, e encadeamentos que dão outros sentidos ao que já estava publicado - quase tudo bastante recente.

Mais de 100 textos foram escritos depois de 2000, um não tinha ainda sido publicado. Perto de 40 nos anos 90 (quase todos em 1995, quando JSM era colaborador regular do Público e escrevia sobre cinema). Menos de 10 nos anos 80. Um é de 1968 (sobre Tati), uma excepção. 
Novos sentidos de que não se suspeitava, se calhar, quando se tinha lido esses mesmos textos (ou quase os mesmos) no tempo deles e dentro do nosso tempo. Muitos estavam então colocados debaixo das palavras (que a mim me agradam) "fora do mercado". Aqui aparecem remodelados, mais que não seja pelo contexto, pelo lugar, pela paginação.

Pelo menos cinco dezenas de textos aqui republicados sairam na secção quinzenal do Mil folhas do Público (2001-2006) a que JSM chamou "Fora do mercado". Em muitos números, era a única rubrica que eu lia. É para mim incompreensivel que a sua colaboração tenha sido dispensada quando o Ye o Mil folhas se fundiram em Ipsilon.

Esta primeira dificuldade é, pois, a de escrever sobre textos que comecei por ler (quase todos) como nascidos de uma vontade de intervenção (não é isso responder que sim a encomendas, escrever nos jornais com regularidade ou frequentemente, enquanto não se é dispensado?), diria mesmo de resistência (ao lugar comum, ao corrente, ao aparente, ao consensual, aos ditames da moda) e que agora são textos-textos, fixados, componentes de um volume com as característica do que está no mercado. 0 seu estatuto mudou. E, com o "estatuto", o sentido. Mas o primeiro sentido não desapareceu.

3.

Volume sem género. A segunda dificuldade: escrever sobre um livro que não tem género e que colhe um pouco de (quase) todos eles. 0 Autor escreve de muitas maneiras em cada linha. Sobre "a vida real" que tem, naturalmente, Arte dentro.

"Pois é". Somos logo avisados na bela e brilhante capa ler o indice onde os nomes de famosos e menos

famosos são muitos, e até se repetem, às vezes en

${ }^{2}$ Sobretudo nos textos que primeiro surgiram em catálogos (de cinema, de pintura). Mas não só

\footnotetext{
${ }^{3}$ Por isso, poucos capitulos há em que a arte

"tratada" é só uma (excepção: o cinema). E nos textos passa-se muitas vezes o mesmo.
} que envolve o objecto que temos nas mãos: "este pode parecer mas não é um diário, são os dias de festa, os centenários, mortes, casamentos, é um calendário privado mas sazonal, mas foi assim que vivi e vivo. São artigos, foram notas que fui escrevendo, algumas que reescrevi, a pedido ou porque me meti no barulho".

E se "diário" não é, já que o Autor o diz, autobiografia também não (mas às vezes parece), e memórias também não (mas são tantas...).

Leiam-se os títulos dos capitulos e as introduções, sobretudo dos primeiros ("Maiores de 12", "Paris ficava no meu quarto"), do capitulo viragem na vida e hiato no livro ("De Renault 4, nas autoestradas"), do último ("Talvez, um gato"), do epilogo ("Revisão da matéria dada"). E não só. Ver as fotografias, mais "do que fez" do que "de quem o fez".
Há memória da infância, da familia, dos pais e da irmã, do colégio e de um castigo, das idas ao cinema; da adolescência e de depois: de viagens, de amigos e de professores (alguns morreram), de cafés, de cidades, de museus, de espectáculos...

Seríamos tentados a considerar Século passado uma literatura-do-eu, de um eu bem concreto, que "viveu e vive" - diz o Autor. E esse viver é (ou quase) o de-todos-os-dias, que todos temos, mas aqui bastante diferente do normal.

A cena no Café Nicola (2005) com que o Autor teve a bela ideia de abrir Século passado, talvez porque está lá tudo (ou quase), é dos exemplos mais claros do convivio entre banal e excepcional, onde entra o poder da coincidência e do trocar-as-voltas que vai seguindo pelo livro fora.

E com sentimentos "à vista" - que todos temos, mas que é costume disfarçar quando sobre artes se escreve - e que aqui são quase sempre especiais. E com vasta (e inquietante) cultura-geral (bem maior e superior à nossa, à do leitor vulgar e mais ainda, se calhar, do actual crítico especializado...), mas que não impede o Autor de ter e cultivar fixações (no grande sentido da palavra) naqueles poucos cineastas, pintores, actores, escritores (poucos, num tão grande mar de gente que conhece) que são os seus, pelos quais batalha. Quase sempre, pelo menos no caso português, menos reconhecidos e chamados do que deveriam ser ${ }^{1}$. Talvez porque incertos, inseguros, inacabados, duvidosos, com qualquer coisa de "arte menor", que pode ser a maior para este eu, que parece (quase) não se esconder no seu "calendário privado".

Portanto, sem rigor científico (como a Academia o entende), subjectivo (como se costuma dizer). Mas é um livro que de crítica (de teatro, de cinema, de literatura, de pintura, de todas as artes um pouco, de música quase não) e de ensaio tem o seu quê $\hat{e}^{2}$.

Mas, mesmo que o classifiquemos com o novo e abrangente termo "não-ficção" de que as listas dos tops se socorrem, o nosso sossego não será duradouro. A epígrafe do livro é uma frase de Simone Weil que diz: "a nossa vida real é, em mais de três quartos, composta de imaginação e de ficção".

Pois é. Género não tem. (E já agora, qual é o assunto, se tem tantos?) Século passado é o encadear do dia-adia na(s) cidade(s) - as permanências, as recorrências, as novidades, os desaparecimentos, os regressos, as transformações - com o que já se viu escrito, filmado pintado, representado - e as artes correspondem-se ${ }^{3}$. É 
isso que vai deslocando (sem esforço) cada texto (quase todos) dos pontos de partida até aos pontos de chegada, não através da análise, da teoria, da metáfora ou da paráfrase ${ }^{4}$, mas do a-propósito, da associação, da comparação, do encavalgamento, no desejo de apanhar (quase) tudo de uma vez só e não por partes. Género (que não existe): itinerário.

4.

À terceira dificuldade (que já está nas duas anteriores) podemos chamar-Ihe incomodidades-do-tempo, o malestar central desta escrita e desta vida ${ }^{5}$ (arriscaria eu), sendo esse mal-estar (raramente confessado) uma necessidade e um valor que levam à descoberta de coincidências e de recusas - lugares da razão de viver.

São as incoincidências do tempo: uma mais nossa entre a primeira leitura e a segunda (primeira dificuldade); outra, tanto de quem lê como de quem escreve - a do tempo que é só de um, sendo de todos nós (segunda dificuldade).

Qualquer coisa que se assemelha ao fenómeno do antes-e-depois, de que se faz a vida: "Tinha visto o filme [Pamplinas maquinista] há uns três anos e parecera-me igual ao que sempre vira. $E_{1}$ como sempre, tinha rido muito. Mas hoje lavei a louça, sentei-me a ver e não ri nada, é que nem uma só vez. / Terá o Pamplinas maquinista morrido como vão morrendo os poemas (ler Valéry sobre La Fontaine)? Que ideia, vi o filme de ponta a ponta, e a sua livre invenção, a sua dinâmica frenética tocou-me fundo, muito fundo, só que não ri. / Eu mudei com certeza, nestes três desamparados anos, mas juro que o filme também." 1995 (pp. 302)

E é o "barulho" onde o Autor "se mete" por ser assim que "viveu e vive": o tempo que foi e ainda é, o tempo que foi e já não é, a diferença da duração de certas coisas, lugares, pessoas, vidas, ideias. 0 tempo cronológico (do mundo e de cada um, com o Autor à cabeça) e o tempo traduzido em épocas de que aqui nascem fulgurantes retratos, aos pedaços ${ }^{6}$.

É nestas incomodidades do tempo que aparece várias vezes o drama (ou o conforto) da idade, escrito por alguém que, inimigo declarado do mito-da-juventude, sempre terá querido crescer (envelhecer) depressa, mesmo depois de atingidos os 12 anos (e os 17, de que fala menos) que o deixaram ver finalmente os muitos filmes da sua vida, ou seja viver.

É assim que diz: "velho, isso mesmo, velho, é isso que eu quero ser" (p. 509). E completa: "A juventude, que maldição!" (p. 136).
Esse tempo nada pacífico puxou-o o autor para título, ampliando nele a subjectividade que o tempo tem, e brincando, como gosta de fazer. Se século é uma medida (objectiva) de tempo, "século passado" não quer dizer (neste momento) o mesmo para todos: se significa (ainda) século XIX para quem nasceu no meio do século XX (como o Autor, como eu), vai significando cada vez mais século XX para quem nasceu depois (ou para quem faz História).

E é o século XX o de muitas destas histórias (que estamos autorizados a chamar fiç̧ões) e que esperaram pelo século XXI para serem narradas.

Claro que o título também pode fazer pensar em coisa muito antiga, coisa que já não volta, às vezes com essa tristeza de o tempo não voltar para trás - o que aqui não acontece. Ou seja, coisa arrumada. Quando é precisamente do contrário que se trata.

Daí precisamente, a saudável ausência do futuro. 0 que chega a ser explicado: "Somos tão feitos de passado mesmo neste dia de hoje, presente, e o futuro não o vemos, nem o vislumbram sequer aqueles que a essa magia tanto afinco dedicam. [...] 0 futuro - e não é só a História, apenas o dia seguinte - limpa-nos, ossuário, retira-nos a velha carne. Tira-nos a vida, dando-Ihe respiração e electricidade. Mas também nos desfigura, nos uniformiza, trapaceia".

Anda por aqui um tratamento do tempo que tem qualquer coisa de Blanqui, comunista do "século passado" (leia-se XIX): "Ocupemo-nos com o hoje. 0 amanhã não nos pertence, não temos nada a ver com ele. 0 nosso único dever é preparar-Ihe bons materiais para o seu trabalho de organização. 0 resto não é da nossa competência"(1971).

5.

A estas dificuldades acrescenta-se uma quarta, derivada do tipo de publicação que me fez a encomenda, uma revista de teatro, portanto lida por gente que vive dele, que vive nele, estudiosos ou fabricantes.

Ora, se bem que o Autor tenha feito teatro desde os tempos da faculdade, primeiro universitário, depois profissional, com uma rápida passagem pelo de amadores; se bem que tenha fundado duas companhias cuja importância nem vale a pena lembrar - uma com Luís Miguel Cintra antes do 25 de Abril (Teatro da Cornucópia), outra sozinho, muitos anos depois (Artistas Unidos) -i se bem que tenha feito estágios com Peter Stein (Alemanha) e Strehler (Itália); se bem que seja actor (em Portugal, em
${ }^{4}$ A propósito de teoria, ver a introdução de "Doutrina, por enquanto" propósito de paráfrase, ver "Louvor da paráfrase. Saudades de Roger Blin".

${ }^{5}$ Raramente explicitado em Século passado. Uma excepção, entre poucas: "o meu coração ficou lá atrás, com aqueles alunos, que vida será a deles, que mundo Ihes vamos deixar?" (p. 468).

${ }^{6} 0$ retrato da segunda metade dos anos 60, que não é feito de uma só vez é particularmente pormenorizado (e entusiasmante) na introdução do V capitulo, "Mesmo agora que anoitece". 
França) $)^{7}$, encenador, e mais recentemente "director de companhia"; se bem que escreva teatro, traduza teatro e tenha sido crítico de teatro, o teatro não é a arte que ocupa mais páginas de Século passado.

"Mais sobre quem me fez do que sobre aquilo que fiz, mais sobre quem me desafia (ou desafiou mas desafia ainda), do que sobre os desafios que fui, também lançando. Um homem feito do que vê, do que ouve, dos passeios, e eu foi assim que fui vivendo, feliz, na passiva" - frases bem à vista na contracapa, vindas da "Nota final".

Por isso, raramente o Autor fala das suas muitíssimas experiências de fabrico - quer no teatro quer no cinema.

Por isso, a literatura-escritores-leitura-edição-livrarias (mais de 30 textos, além de referências noutros) e a pintura-pintores-exposições-museus (perto de 30 textos, além de referências noutros) têm um peso considerável no volume.

Por isso, o pouco teatro e o muito cinema: o muito teatro foi vivido sobretudo "na activa"; muito do imenso cinema, "na passiva".

São dois os capítulos todos (ou quase) sobre cinema (II, VIII), são dois os capítulos com muitos textos sobre cinema (I, VI), não o cinema que JSM fez, mas aquele que viu. Cerca de um quarto dos textos do livro. 0 cinema, esse "principio de conversa". E alguma coisa mudou desde a ânsia de ter 12 anos: "Agora, vou pouco ao cinema, passam as semanas. E não vejo filmes na televisão, nem uso os dvds a não ser para assuntos profissionais. Fico aqui em casa. Também não tenho ninguém com quem conversar sobre os filmes - e o que é um filme a não ser um principio de conversa?" (p. 415) gente de teatro (cerca de 20) e muitos outros em que o teatro entra. Amélia

Rey Colaço, o Teatro Moderno e dois textos sobre Glicinia Quartin estão no Cap. I; Artur Ramos, no V; Strehler, no VII; Roger Blin e Harold Pinter, no X. Com tudo o que anda à volta.

\begin{abstract}
... encanta-me o teatro, este sitio impossivel onde pessoas vindas de tantos sitios diferentes se unem por semanas, por dias, em volta de um texto vindo de outro lugar, vindo de longe e de há tanto tempo, se unem numa esperança, num amor. (p. 199)
\end{abstract}

0 teatro, parcela da história de uma (auto)formação que nunca acaba, aparece a propósito de homenagens (de tipo diferente) a Pessoas para o Autor determinantes, vários esquecidos ou em vias disso (e não só porque o teatro é mais efémero do que a literatura, a pintura, o cinema): Glicínia Quartin, Isabel de Castro, Augusto Figueiredo, Jacinto Ramos, Cecilia Guimarães, Artur Ramos... e também Amélia Rey Colaço. E há ainda referências a gente, alguns bem novos, com quem trabalha.

Porque não é na juventude que nos formamos, maldita maldição: é no resto da vida (que não é nenhum cruzeiro mas trambolhões e solavancos) que em nós fazemos as rugas que tão bem filmou Varda. Ou a calvicie de Piccoli, cabelos que a vida matou. (p. 138)

6.

Deixo para último, nesta lista de dificuldades, aquela que deveria ter aparecido primeiro: as relações que tenho com o Autor e o ter vivido com ele alguns acontecimentos, lugares, épocas, e conhecido gente de que aqui se vai falando (que bom!). E que, como é natural, conheci e vivi às vezes diferentemente, noutras situações e por outras razões. É o tal direito-à-diferença (no sentido não estafado do termo) que esta obra, para além do resto, nos dá.

Mais dificil ainda, portanto, escrever sobre Século passado, por ser o livro de alguém com quem me cruzei mais do que uma vez. Sobretudo num viver "na activa", que não é aqui, voluntariamente, o assunto. Mas acontece que foi nesse viver "na activa" que fui encontrando "quem me fez", também o Autor, e muito pelos "desafios" que foi "lançando" aos outros, em tempos de muitos inimigos, o que aqui não é (quase) tema.

Admito que ir buscar textos mais antigos estragasse a unidade da escrita deste volume, que é um valor. Admito que o "século passado" escrito no século seguinte se veja melhor. Mas sinto a falta de textos sobre (e de) tempos 


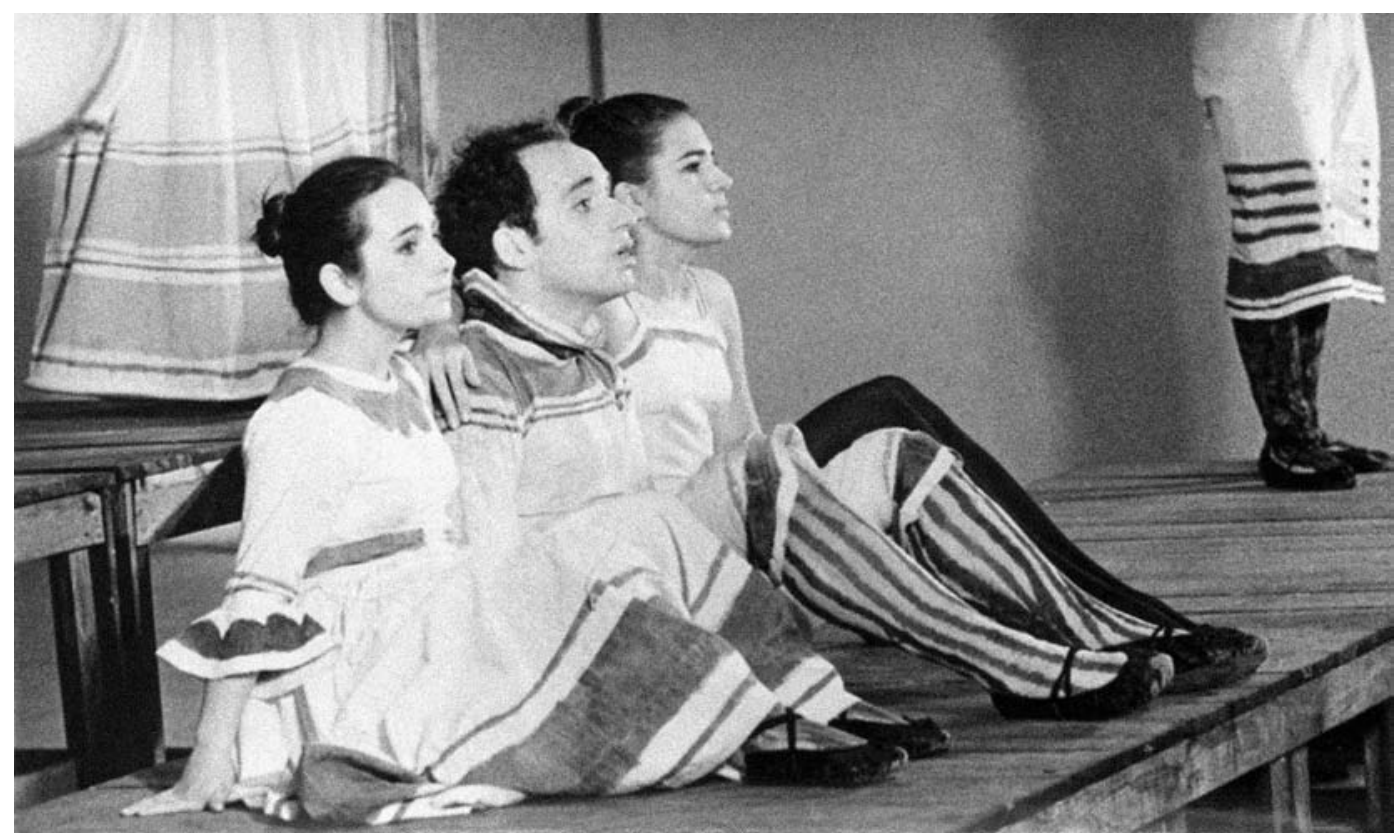

daqui ausentes. Terão sido, percebo, mais importantes para a minha formação do que para a do Autor, cuja vida se fez, ao contrário da minha, (quase) sempre nos mundos das artes.

Tenho pena que a obrigação de escolher (para o livro não ter 1000 páginas...) não tenha trazido até às 500 publicadas coisas como estas: as pateadas (ao Nacional e a outros teatros); o Anfitrião que fizemos em 69, mais as suas tournées; a curta passagem pelo Ateneu Cooperativo logo a seguir, esse Cervantes na SNBA mais os embates com os mundos das políticas; algumas férias e passeios (há uma fotografia, é verdade) com projectos dentro; os demolidores textos sobre espectáculos, filmes, textos (1971-72) na Crítica (referida na p. 528); os complicados 74-75 onde cada um estava no seu lugar; bem mais tarde, a escrita a várias mãos dos textos para a primeira campanha das europeias do PSR (1987).

E também me apetecia que aparecesse mais a ida ao Festival de Avignon em 68 (há cinco fotografias, é verdade), onde pela primeira vez vi Straub, Garrel (p. 274) e em que assistimos à estreia dos Baisers volés do Truffaut no Palácio dos Papas, e a debates; que houvesse mais textos do jornal Combate (há um, p. 297); que houvesse outros ligados à associação Abril em Maio que nasceu em 1994 (há um, publicado na revista AEM, p. 455). Penso em declarações de princípios, propostas, para mim bem mais do que isso... Penso em intervenções - no colóquio "Em tempo de Expo há outras histórias para contar" ("A arte para os novos reis", já publicada em livro, bem sei) ou nos colóquios Estaca zero ("Deus, Pátria, Autoridade já fizeram filhos"), etc. etc.

É assim. E outros, que também viveram pedaços de vida com o Autor, sentirão outras faltas.

Faltas em parte explicadas no próprio livro, eu li: "Não, não procurei o que escrevi - se é que escrevi coisas de jeito, a memória inebria-se, ao pensar - naqueles anos, entre 1972 e 1979, em que terei vivido a criação e os primeiros, difíceis anos do Teatro da Cornucópia. Nem falo quase do Luis. É assim mesmo, um homem não chora" (p. 375).
E mais difícil ainda é para mim escrever sobre Século passado quando nele se diz: "Não encontrei todos os textos que me lembro de ter escrito nem encontrei nada sobre autores que, mais até do que outros, me fizeram". Na lista que se seque a isto: "Eduarda Dionísio, a escritora" [que talvez tenha sido] "e também a amiga" [que seguramente sou].

7.

Tentando então não cair no favoritismo (ou na excessiva exigência) a que as minhas estreitas relações com o Autor levarão certamente, e sobretudo tentando imaginar os leitores a que estas linhas se destinam, só não tenho dificuldade em thes propor os modos-de-usar deste livro, tão singular como a vida e a obra de quem o escreveu: a ler como manifesto - contra a especialização e fechamento ao mundo-mundo para que tendem as gentes dos teatros e o seu fazer; a usar como instrumento - contra o esquecimento, apagamento, alheamento das formas de dizer, de fazer, de viver (que já houve e continua a haver) que nem sempre garantem o que se chama sucesso nem são maioritárias, como se diz, por vezes mais difíceis mas nem sempre, e daqueles que viveram nelas; a consultar como fonte - de informações, e tantas aqui são tão raras.

Manifesto, instrumento, fonte. Tanto por aquilo de que fala como pela maneira de o fazer.

Termino com uma viva saudação à ausência de índice onomástico, que contraria a nossa preguiça e nos ajuda a descobrir tanta coisa. E é para isso sobretudo que (o) Século passado serve.

\section{Referência bibliográfica}

BLANQUI, Auguste (1971), "Critique Sociale", in Auguste Blanqui: Textes choisis, pref. e notas de V.P. Volguine, Paris, Editions Sociales. 